\title{
Financial Assessment on Designing Inventory Policy by Considering Demand, Lead Time, and Defective Product Uncertainties: A Monte Carlo Simulation
}

\author{
Zakka Ugih Rizqi ${ }^{1}$, Adinda Khairunisa ${ }^{2}$, Aniya Maulani ${ }^{2}$ \\ ${ }^{1}$ Department of Industrial Management, National Taiwan University of Science and Technology, Taiwan \\ ${ }^{2}$ Department of Industrial Engineering, Universitas Islam Indonesia, Indonesia
}

\begin{abstract}
Inventory is one of the main components in supply chain. However, it is not easy to design inventory policy under uncertainties. The frequent occurrence of overstocks increases the company's financial expenditure. Otherwise, stockout decreases customer satisfaction and damage the company's image. This study aims to provide monte carlo model to design inventory policy with the aim of maximizing net income with a variety of uncertainties, one of the uncertainties is defective product because of the travel from suppliers. To handle the complexity and uncertainty of problem, a Monte Carlo simulation is used with spreadsheetbased representation. To test the reliability of the model, guitar company is used as relevant use case with uncertainty adhered 'the greater number of order quantity, the greater likely the defective guitar will be'. The verification \& validation process, experimental design, and alternative selection are also done with statistical tests. Based on the simulation result, it is known that changing the reorder point to 80 and the order quantity to 90 gives the best result which can increase net income by $0.44 \%$ compared to the initial net income. In addition, the number of stockouts has decreased.
\end{abstract}

\section{CONTACT}

ugihzakka@gmail.com

\section{KEYWORDS}

Inventory, Monte Carlo Simulation, Defective Product, Stockout, Supplier

\section{INTRODUCTION}

Guitar is one of the most popular musical instruments compared to other musical instruments [1]. This is because the price is not too expensive and also the convenience to carry everywhere. Generally acoustic guitars are often used to accompany singers, or even to play solo instrumentals. Now, almost everyone has a guitar, good for playing in the room, to make money by covering songs that are then uploaded to social media or to play in cafes. Therefore, the public interest in acoustic guitars continues to increase so that companies engaged in the production of acoustic guitars take advantage of this opportunity to achieve maximum profits.

ZackGuitar is one of the companies that sell acoustic guitar in Indonesia. ZackGuitar did not produce his own acoustic guitar, but was obtained from a ZikiZiba supplier from Taiwan. ZikiZiba has been trusted that the acoustic guitar supplied have excellent quality seen from the guitar model and the sound quality produced by the guitar. However, due to distant shipments, there are always uncertainty of number of defective guitars, the greater number of order quantity, the greater likely the defective guitar will be. Supplier has rules that the guitars sold cannot be returned with any reasons. Therefore, if the defective guitars received by ZackGuitar is high, it is worried that the company will lose. Defective guitars will be sold immediately to reduce the amount of loss at a cheaper price than the purchase price. To differ its guitar with others, ZackGuitar only gave a little variation by adding a batik pattern.

ZackGuitar is known as a seller of acoustic guitars that can be trusted by his customers, because guitars that are sold have good durability (not easily damaged). Therefore, guitars that are sold are quite expensive when compared to other guitars. Although the price is quite expensive, it still makes guitar lovers to buy it. Even guitars sold are often used up every day due to heavy demand. As a result of frequent stockouts, it has a negative impact on customer satisfaction [2]. Because it makes consumers often disappointed and gives a bad image to the company. This also had an impact on the profits obtained by the ZackGuitar company. The company feels that the profits obtained are not maximized, the company is worried that raising the selling price of each guitar will reduce the number of consumers because the prices pegged are quite expensive.

Currently, the company has alternatives to reduce stockouts that occur by increasing the number of orders from supplier and requiring inventory. Common problems in inventory management are stockout and overstock [3]. Therefore, it is necessary to evaluate which alternative can balance the stockout that occurs with overstock so that it is profitable for the company. However, the company is worried that if the number of guitars ordered from supplier are increased, the number of defective guitars will increase as well. While changing suppliers cannot be done because the customer already likes the quality of the guitar from the supplier. 
Based on the background that has been stated, the purpose of this study is to determine the effect of the alternatives given to the number of defective guitars that will be obtained which will affect the total profit obtained by the company. And also, to find out the alternatives given whether it can balance the number of stockouts with overstock that occurs. Therefore, in this study monte carlo simulation will be used by using Microsoft Excel which is spreadsheet-based representation. Spreadsheet is powerful tool and also quite convenient for simulation modeling, but it has four important disadvantages which are data structure limitation, hardness to implement complex algorithm, not fast enough for a lot of scenarios, and data storage limitation [4]. By implementing simulation, the losses of money and time from experiments given can be minimized [5].

Previous studies have conducted similar topics for designing inventory policy by using monte carlo simulation approach with different variables considered. Ramadan et al. (2020) [6] used monte carlo by considering probabilistic supply cost, Widyadana et al. (2017) [7] and Andriansyah et al. (2018) [8] considered intermittent demand as stochastic variable, Leepaitoon \& Bunterngchit (2019) [9] applied monte carlo simulation for retail store by considering probabilistic lead time and demand, Belvárdi et al. (2012) [10] also used the same approach to simulate complex multi-echelon supply chains with their own interactive simulator. Compared with the previous researches, there is still no research in inventory problem that considers defective product as stochastic variable and analysis its effect on the inventory cost. However, practically that condition often happens where defective product occurs and cost the company. This research intends to include defective product as a stochastic variable from inventory perspective and learn its effect on inventory cost to determine a better policy for inventory improvement.

\section{METHODS}

\section{Data Collection}

There are several data taken in this study, namely reorder point, order quantity, warehouse capacity, and inventory cost which is obtained through interview with head section of inventory department who know the conditions of inventory and warehouse in ZackGuitar. In addition, researcher also uses some data from historical data like probabilistic demand, leadtime and defective product that company gets due to shipping from supplier

\section{Simulation Modelling}

In simulation modeling, monte carlo is used. Monte carlo is basically mathematical technique to predict the possible outcomes of an uncertain event based on sampling process of certain probability distribution. Monte Carlo is chosen because it does not need sophisticated software and does not explicitly contain time variable that makes simulation very expensive to run. It was built by using Microsoft Excel. It has been able to generate independent and uniform random numbers needed which both conditions are the main requirements of valid random numbers. Empirical probability distribution is made for uncertainty variables such as demand, lead time and defective product from historical data. In this stage, mathematical equations are made to model the relationship between variables using functions available in Microsoft Excel such as the Vlookup, IF, Random Number Generator and other relevant functions. The Monte Carlo model is then simulated for 1 month.

\section{Model Validation}

The model that has been constructed needs to be enhanced by using validation testing to see credibility of the model [4]. Validation can be done by comparing the output of the simulation result with the actual system [11]. In this study, non-parametric statistical tests are carried out by comparing the output of the simulation model with the actual system by using Chi-Square Test. The variable used to compare is the total profit for a month. ChiSquare test is used to test whether the frequency differences obtained from the two samples (model and real system) were significant differences or not [12]. The Chi Square test is very suitable to use when historical data is insufficient and a very dynamic system environment. The model will not be experimented if the model has not passed the validation stage.

\section{Alternative Selection}

Alternative selection is done by comparing the model of real system net profit with the scenarios that have been made. In the alternative selection steps, two tests will be carried out, namely One-way Analysis of Variance (Anova) and Bonferroni test. Anova is used to test the average difference between the initial models and other scenarios [13]. If Ho is accepted (there is no difference between the initial model and other scenarios), it means that the scenarios that have been made do not give significantly different results from the initial model. Whereas if Ho is rejected, then proceed with the Bonferroni test to see which of these scenarios are different from the original model and give the best result [14]. 


\section{RESULTS AND DISCUSSIONS}

\section{Monte Carlo Simulation}

Before the simulation is executed, it is necessary to make probability distributions as random number constraints using Lower Limit (LL) and Upper Limit (UL). Probability distributions are based on company historical data in the form of Demand showed in Table 1, Lead Time showed in Table 2 and Number of defective products arising from shipping goods of supplier for 60 guitars ordered in Table 3, Number of defective products for 80 guitars ordered showed in Table 4 and Number of defective products for 90 guitars ordered showed in Table 5 .

Table 1. Demand probability distribution.

\begin{tabular}{cccccc}
\hline $\begin{array}{c}\text { Demand } \\
\text { (unit) }\end{array}$ & Frequency & Probability & Cumulative Probability & LL & UL \\
\hline 30 & 11 & 0,11 & 0,11 & 1 & 11 \\
38 & 12 & 0,12 & 0,23 & 12 & 23 \\
45 & 13 & 0,13 & 0,36 & 24 & 36 \\
48 & 9 & 0,09 & 0,45 & 37 & 45 \\
50 & 10 & 0,1 & 0,55 & 46 & 55 \\
54 & 15 & 0,15 & 0,7 & 56 & 70 \\
57 & 5 & 0,05 & 0,75 & 71 & 75 \\
61 & 6 & 0,06 & 0,81 & 76 & 81 \\
65 & 8 & 0,08 & 0,89 & 82 & 89 \\
70 & 11 & 0,11 & 1 & 90 & 100 \\
\hline Total & 100 & & & & \\
\hline
\end{tabular}

Table 2. Lead time probability distribution.

\begin{tabular}{cccccc}
\hline $\begin{array}{c}\text { Lead Time } \\
\text { (day) }\end{array}$ & Frequency & Probability & Cumulative Probability & LL & UL \\
\hline 1 & 25 & 0,23 & 0,23 & 1 & 23 \\
2 & 37 & 0,35 & 0,58 & 24 & 58 \\
3 & 45 & 0,42 & 1 & 59 & 100 \\
\hline Total & 107 & & & & \\
\hline Table 3. Number of defective products for 60 guitars ordered probability distribution. \\
\hline Number of & & & & & \\
Defective & Frequency & Probability & Cumulative Probability & LL & UL \\
Guitars & & & & & \\
(unit) & 14 & 0,28 & 0,28 & 1 & 28 \\
\hline 3 & 17 & 0,34 & 0,62 & 29 & 62 \\
4 & 10 & 0,2 & 0,82 & 63 & 82 \\
5 & 9 & 0,18 & 1 & 83 & 100 \\
\hline 6 & 50 & 1 & &
\end{tabular}




\begin{tabular}{|c|c|c|c|c|c|}
\hline $\begin{array}{l}\text { Number of } \\
\text { Defective } \\
\text { Guitars } \\
\text { (unit) }\end{array}$ & Frequency & Probability & Cumulative Probability & LL & UL \\
\hline 3 & 9 & 0,18 & 0,18 & 1 & 18 \\
\hline 4 & 14 & 0,28 & 0,46 & 19 & 46 \\
\hline 5 & 17 & 0,34 & 0,8 & 47 & 80 \\
\hline 6 & 10 & 0,2 & 1 & 81 & 100 \\
\hline Total & 50 & 1 & & & \\
\hline
\end{tabular}

Table 5. Number of defective products for 90 guitars ordered probability distribution.

\begin{tabular}{cccccc}
\hline $\begin{array}{c}\text { Number of } \\
\text { Defective } \\
\begin{array}{c}\text { Guitars } \\
\text { (unit) }\end{array}\end{array}$ & Frequency & Probability & Cumulative Probability & LL & UL \\
\hline 3 & 6 & 0,12 & 0,12 & 1 & 12 \\
4 & 13 & 0,26 & 0,38 & 13 & 38 \\
5 & 19 & 0,38 & 0,76 & 39 & 76 \\
6 & 12 & 0,24 & 1 & 77 & 100 \\
\hline Total & 50 & 1 & & & \\
\hline
\end{tabular}

After the probability distribution has been made, Monte Carlo simulation modeling and its mathematical equations are made based on spreadsheet representation and relation. Then verification of the model is done by changing some variables into extreme value to see if all equations have been made correctly. The verified simulation model can be seen in Figure 1.

\section{Validation}

Chi-Square test is used to validate the model by comparing the total profit for a month in model with the actual system. By using 95\% confidence level, it was found that $\chi 2$ calculated $=13.26$ which is less than $\chi 2$ table $=19.67$, so Ho is received. It means that there is no difference between the frequency of simulation data and the frequency of historical data. In other words, the simulation model can be used for experiment to find the best alternatives because the simulation model can respresent the real system.

\section{Experimental Design}

After the simulation was carried out using the MonteCarlo method, it was found that the average net profit of the 30 replications obtained by the ZackGuitar company was Rp269.655.333/month. Net profit is obtained from Equation 1.

Net profit $=$ Gross Profit - Maintenance Cost - Batik Fee - Defect Losses

ZackGuitar wants to increase its net profit. Because the selling price of guitars is too expensive, so the selling price of the guitar / unit will not be raised. So that we try to change other variables to increase company revenue. In this study, there are 2 variables that can be changed, first is reorder point and second is order quantity. 


\begin{tabular}{|c|c|c|c|c|c|c|c|c|c|c|c|c|c|c|c|}
\hline Day & $\begin{array}{c}\mathrm{RN} \text { of } \\
\text { Demand }\end{array}$ & $\begin{array}{c}\text { RN of Lead } \\
\text { Time }\end{array}$ & $\begin{array}{l}\text { Total Demand } \\
\text { (unit) }\end{array}$ & Lead Time (day) & $\begin{array}{l}\text { Initial Inventory } \\
\text { (unit) }\end{array}$ & $\begin{array}{l}\text { Final Inventory } \\
\text { (unit) }\end{array}$ & $\begin{array}{r}\text { Sold } \\
\text { (unit) }\end{array}$ & $\begin{array}{c}\text { Overstock } \\
\text { (unit) }\end{array}$ & $\begin{array}{c}\text { Stockout } \\
\text { (unit) }\end{array}$ & $\begin{array}{l}\text { Gross Profit } \\
\text { (IDR) }\end{array}$ & $\begin{array}{l}\text { Maintenance } \\
\text { cost (nviah) }\end{array}$ & \begin{tabular}{|c|} 
Stockout \\
Losses (DRR) \\
\end{tabular} & $\begin{array}{c}\text { Batik Fee } \\
\text { (IDR) }\end{array}$ & $\begin{array}{c}\mathrm{RN} \text { of Defective } \\
\text { Gruitars }\end{array}$ & \begin{tabular}{|c|} 
Defective \\
Guitars (unit)
\end{tabular} \\
\hline 1 & 27 & 28 & 4551 & NOT BOOKING & 100 & 55 & \begin{tabular}{r|}
45 \\
\end{tabular} & \begin{tabular}{|l|}
55 \\
\end{tabular} & 0 & 22500000 & 1100000 & \begin{tabular}{|l|}
0 \\
\end{tabular} & 4000000 & 84 & 0 \\
\hline 2 & 6 & 64 & 301. & NOT BOOKING & 55 & 25 & 30 & 25 & 0 & 15000000 & 500000 & 0 & 0 & 38 & 0 \\
\hline 3 & 55 & 84 & 50 & 3 & 25 & 0 & 25 & 0 & 25 & 12500000 & 0 & 5000000 & 0 & 84 & 0 \\
\hline 4 & 76 & 58 & 61 & 2 & 0 & 0 & 0 & 0 & 61 & 0 & 0 & 12200000 & 0 & 55 & 0 \\
\hline 5 & 78 & 77 & 61 & & 0 & 0 & 0 & 0 & 61 & 0 & 0 & 12200000 & 0 & 52 & 0 \\
\hline 6 & 4 & 7 & 30 & ARRIVAL ORDER & 60 & 30 & 30 & 30 & 0 & 15000000 & 600000 & 0 & 2400000 & 6 & 3 \\
\hline 7 & 49 & 84 & 50 & 3 & 30 & 0 & 30 & 0 & 20 & 15000000 & 0 & 4000000 & 0 & 54 & 0 \\
\hline 8 & 83 & 30 & 65 & & 0 & 0 & 0 & 0 & 65 & 0 & 0 & 13000000 & 0 & 69 & 0 \\
\hline 9 & 68 & 30 & 54 & & 0 & 0 & 0 & 0 & 54 & 0 & 0 & 10800000 & 0 & 60 & 0 \\
\hline 10 & 7 & 72 & 30 & ARRIVAL ORDER & 60 & 30 & 30 & 30 & 0 & 15000000 & 600000 & 0 & 2400000 & 32 & 4 \\
\hline 11 & 86 & 15 & 65 & & 30 & 0 & 30 & 0 & 35 & 15000000 & 0 & 7000000 & 0 & 59 & 0 \\
\hline 12 & 76 & 28 & 61. & ARRIVAL ORDER & 60 & 0 & 60 & 0 & 1 & 30000000 & 0 & 200000 & 2400000 & 46 & 4 \\
\hline 13 & 51 & 78 & 50 & 3 & 0 & 0 & 0 & 0 & 50 & 0 & 0 & 10000000 & 0 & 86 & 0 \\
\hline 14 & 69 & 85 & 54 & 2 & 0 & 0 & 0 & 0 & 54 & 0 & 0 & 10800000 & 0 & 16 & 0 \\
\hline 15 & 53 & 24 & 50 & & 0 & 0 & 0 & 0 & 50 & 0 & 0 & 10000000 & 0 & 24 & 0 \\
\hline 16 & 87 & 4 & 65. & ARRIVAL ORDER & 60 & 0 & 60 & 0 & 5 & 30000000 & 0 & 1000000 & 2400000 & 84 & 6 \\
\hline 17 & 13 & 81 & 38 & 3 & 0 & 0 & 0 & 0 & 38 & 0 & 0 & 7600000 & 0 & 68 & 0 \\
\hline 18 & 48 & 27 & 50 & 2 & 0 & 0 & 0 & 0 & 50 & 0 & 0 & 10000000 & 0 & 29 & 0 \\
\hline 19 & 62 & 61 & 54 & & 0 & 0 & 0 & 0 & 54 & 0 & 0 & 10800000 & 0 & 15 & 0 \\
\hline 20 & 77 & 73 & 61. & ARRIVAL ORDER & 60 & 0 & 60 & 0 & 1 & 30000000 & 0 & 200000 & 2400000 & 83 & 6 \\
\hline 21 & 81 & 24 & 61 & & 0 & 0 & 0 & 0 & 61 & 0 & 0 & 12200000 & 0 & 83 & 0 \\
\hline 22 & 18 & 42 & 38. & ARRIVAL ORDER & 60 & 22 & 38 & 22 & 0 & 19000000 & 440000 & 0 & 2400000 & 15 & 3 \\
\hline 23 & 81 & 17 & 61 & & 22 & 0 & 22 & 0 & 39 & 11000000 & 0 & 7800000 & 0 & 69 & 0 \\
\hline 24 & 3 & 40 & 30. & ARRIVAL ORDER & 60 & 30 & 30 & 30 & 0 & 15000000 & 600000 & 0 & 2400000 & 3 & 3 \\
\hline 25 & 3 & 33 & 30 & 2 & 30 & 0 & 30 & 0 & 0 & 15000000 & 0 & 0 & 0 & 50 & 0 \\
\hline 26 & 3 & 81 & 30 & & 0 & 0 & 0 & 0 & 30 & 0 & 0 & 6000000 & 0 & 66 & 0 \\
\hline 27 & 22 & 39 & 38. & ARRIVAL ORDER & 60 & 22 & 38 & 22 & 0 & 19000000 & 440000 & 0 & 2400000 & 21 & 3 \\
\hline 28 & 44 & 64 & 48 & 3 & 22 & 0 & 22 & 0 & 26 & 11000000 & 0 & 5200000 & 0 & 9 & 0 \\
\hline 29 & 69 & 27 & 54 & 2 & 0 & 0 & 0 & 0 & \begin{tabular}{l|l}
54 \\
\end{tabular} & o & 0 & 10800000 & 0 & 42 & 0 \\
\hline 30 & 15 & 94 & \begin{tabular}{l|l|l}
38 & -10 \\
\end{tabular} & & 0 & 0 & 0 & 0 & \begin{tabular}{l|l|l}
38 & - \\
\end{tabular} & 0 & 0 & 7600000 & 0 & 99 & 0 \\
\hline \multicolumn{7}{|c|}{ Total } & 580 & 214 & 872 & 290000000 & 4280000 & 174400000 & 23200000 & & 32 \\
\hline
\end{tabular}

Figure 1. Simulation model of real system.

In the first alternative (model of real system), the company requires a reorder point of 45 products and order quantity is 60 products. In the second alternative (scenario 1), the researcher will try to increase the reorder point to 60 and increase the order quantity to 80 . In the third alternative (scenario 2), the researcher will try to increase the reorder point to 80 and increase order quantity to 90 . It is done because the company still has sufficient warehouse capacity so that the alternatives provided can be applied by the company. The results of the experimental design carried out in 30 replications of the company's net profit for 1 month can be seen in Table 6 .

Table 6. Experimental design result of company's net profit for 1 month.

\begin{tabular}{cccc}
\hline Replication & Model of Real System & Scenario 1 & Scenario 2 \\
\hline 1 & $\mathrm{Rp} 262.260 .000,00$ & $\mathrm{Rp} 334.820 .000,00$ & $\mathrm{Rp} 370.020 .000,00$ \\
2 & $\mathrm{Rp} 289.320 .000,00$ & $\mathrm{Rp} 371.080 .000,00$ & $\mathrm{Rp} 404.600 .000,00$ \\
$:$ & $:$ & $:$ & $:$ \\
30 & $\mathrm{Rp} 288.920 .000,00$ & $\mathrm{Rp} 418.620 .000,00$ & $\mathrm{Rp} 461.540 .000,00$ \\
\hline Average & $\mathrm{Rp} 269.655 .333,00$ & $\mathrm{Rp} 352.078 .667,00$ & $\mathrm{Rp} 388.959 .333,00$ \\
\hline
\end{tabular}

\section{Alternative Selection Results}

Alternative selection is done by comparing between the model of real system net profit, scenario 1 and scenario 2. In the alternative selection steps, 2 tests will be carried out, namely Anova and Bonferroni. Following are the steps:

\section{- Anova Test}

Using a confidence interval: $95 \%$, so the probability of error $(\alpha): 5 \%=0.05$. The Anova test results can be seen in Figure 2 . 


\begin{tabular}{|c|c|c|c|c|c|c|}
\hline SUMMARY & & & & & & \\
\hline Groups & Count & Sum & Average & Variance & & \\
\hline Model of Real System & 30 & 7261960000 & 242065333,3 & $5,73046 \mathrm{E}+14$ & & \\
\hline Scenario 1 & 30 & 9368460000 & 312282000 & $8,62541 \mathrm{E}+14$ & & \\
\hline Scenario 2 & 30 & 10453810000 & 348460333,3 & $1,21781 \mathrm{E}+15$ & & \\
\hline \multicolumn{7}{|l|}{ ANOVA } \\
\hline Source of Variation & SS & df & MS & $\mathrm{F}$ & P-value & F crit \\
\hline Between Groups & $1,75591 \mathrm{E}+17$ & 2 & $8,77957 \mathrm{E}+16$ & 99,26404012 & $3,53479 \mathrm{E}-23$ & 3,101295757 \\
\hline Within Groups & $7,69486 \mathrm{E}+16$ & 87 & $8,84467 \mathrm{E}+14$ & & & \\
\hline Total & $2,5254 \mathrm{E}+17$ & 89 & & & & \\
\hline
\end{tabular}

Figure 2. Result of anova test.

The value of $\mathrm{F}$ count $=99.26404012$, while the value of $\mathrm{F}$ table $=3.101295757$. Because the value of $\mathrm{F}$ count $>\mathrm{F}$ table, then Ho is rejected, so that there is a difference in average net profit generated by 3 different models both the model of real system, scenario 1 , \& scenario 2 . Because there are differences, it is followed by the Bonferroni test to find out which model gives significantly different results and then take the best alternative.

\section{- Bonferroni Test}

Using a confidence interval: $95 \%$, so the probability of error $(\alpha): 5 \%=0.05$. The Bonferroni test results can be seen in Fig. 3 by comparing each model so that there are 3 comparison results, namely between the model of real system with scenario 1 , the model of real system with scenario 2 , and scenario 1 with scenario 2 .

\begin{tabular}{|c|c|c|c|c|c|}
\hline & Model of Real System Scenario 1 & \multicolumn{4}{|c|}{ Model of Real Systen Scenario 2} \\
\hline Mean & 242065333,3 & \multicolumn{2}{|l|}{ Mean } & 242065333,3 & 347804828 \\
\hline Variance & $5,73046 \mathrm{E}+14 \quad 8,62541 \mathrm{E}+14$ & \multicolumn{2}{|l|}{ Variance } & $5,73046 \mathrm{E}+14$ & $1,248 \mathrm{E}+15$ \\
\hline Observations & $30 \quad 30$ & \multicolumn{2}{|l|}{ Observations } & 30 & 29 \\
\hline Pooled Variance & $7,17793 \mathrm{E}+14$ & \multicolumn{2}{|l|}{ Pooled Variance } & $9,04581 E+14$ & \\
\hline Hypothesized Mean Differenc & 0 & \multicolumn{2}{|c|}{ Hypothesized Mean Difference } & 0 & \\
\hline df & 58 & \multicolumn{2}{|l|}{ df } & 57 & \\
\hline t Stat & $-10,15046882$ & \multicolumn{2}{|l|}{ t Stat } & $-13,5004182$ & \\
\hline$P(T<=t)$ one-tail & $8,89743 \mathrm{E}-15$ & \multicolumn{2}{|l|}{$P(T<=t)$ one-tail } & $1,05306 \mathrm{E}-19$ & \\
\hline t Critical one-tail & 1,671552762 & \multicolumn{2}{|l|}{ tCritical one-tail } & 1,672028888 & \\
\hline$P(T<=t)$ two-tail & $1,77949 \mathrm{E}-14$ & \multicolumn{2}{|l|}{$\mathrm{P}(\mathrm{T}<\mathrm{t}=\mathrm{t})$ two-tail } & $2,10612 E-19$ & \\
\hline tCritical two-tail & 2,001717484 & \multicolumn{2}{|l|}{ t Critical two-tail } & 2,002465459 & \\
\hline$\alpha / n=0.016666667$ & & \multicolumn{2}{|c|}{$\alpha / n=0.0166666667$} & & \\
\hline & & \multicolumn{2}{|l|}{ Scenario 1} & & \\
\hline & Mean & 311509310,3 & 347804827,6 & & \\
\hline & Variance & $8,74795 \mathrm{E}+14$ & $1,24796 E+15$ & & \\
\hline & Observations & 29 & 29 & & \\
\hline & Pooled Variance & $1,06138 \mathrm{E}+15$ & & & \\
\hline & Hypothesized Mean Differenc & a $\quad 0$ & & & \\
\hline & df & \multicolumn{2}{|l|}{56} & & \\
\hline & t Stat & \multicolumn{2}{|l|}{$-4,242311249$} & & \\
\hline & $\mathrm{P}(\mathrm{T}<=\mathrm{t})$ one-tail & \multicolumn{2}{|l|}{ 4,19047E-05 } & & \\
\hline & t Critical one-tail & \multicolumn{2}{|l|}{1,672522303} & & \\
\hline & $P(T<=t)$ two-tail & \multicolumn{2}{|l|}{$8,38094 \mathrm{E}-05$} & & \\
\hline & tCritical two-tail & \multicolumn{2}{|l|}{2,003240719} & & \\
\hline & $\alpha / n=0.016666667$ & & & & \\
\hline
\end{tabular}


Based on the testing criteria that if $\mathrm{P}(\mathrm{T}<=\mathrm{t})$ two-tail $<\alpha / \mathrm{n}$ then Ho is accepted. Looking at Figure 3 all comparisons show that $\mathrm{P}(\mathrm{T}<=\mathrm{t})$ two-tail $<\alpha / \mathrm{n}$ which means Ho is accepted or there is a difference in the average net profit a month between each alternative given. Then the next step is choosing alternatives that give the best results. Based on the experimental results of the second alternative (scenario 1), it was found that the net profit increased to $\operatorname{Rp} 352,078,667.00$ which was originally $\mathrm{Rp} 269,655,333.00$. Whereas in the third alternative (scenario 2) it can be seen that the profit increases to Rp. 388,959,333.00 which is greater $0.44 \%$ than initial net profit. So that it can be said that the two alternatives provide better changes to the problem of net profit, where scenario 2 has the best profit because it has the highest value and greater $0.44 \%$ than initial net profit.

Based on the simulation results for 30 replications, it was found that the average stockout obtained in scenario 2 was lower than the initial model even though the overstock amount was greater. This is not a problem because the decrease in stockout has a larger presentation than the increase in overstock. And the company still has enough capacity to accommodate the amount of overstock. Because the main goal of the company is to increase its net income so that the increasing in overstock is still acceptable. Whereas if analyzed in terms of the number of defective guitars based on the alternatives given, the more the number of order quantity, the more the number of defective guitars. But the company does not need to worry, because the change in the number of guitars that are sold is more than the change in the number of defective guitars so that it will still increase revenue from the company itself.

\section{CONCLUSIONS}

Based on the discussion above, it can be concluded that alternative 3 is the best alternative that can be applied by the company because it can increase net income by $0.44 \%$ compared to initial net income and can reduce the amount of stockout that occurs so that customer satisfaction can be maintained. It can be done by the company by increasing the reorder point to 80 and the order quantity to 90 . However, scenario 2 also makes the number of defective guitars higher. But the company does not need to worry, because the change in the number of guitars that are sold is more than the change in the number of defective guitars so that it will still increase the company's profits.

\section{REFERENCES}

[1] Zoran A, Joseph AP. The chameleon guitar - guitar with a replaceable resonator. Journal of New Music Research 2011; 40: 59-74.

[2] Gacan JF. Consumer response to stockouts. Journal of Consumer Research 200; 27: 249-266.

[3] Satibi A, Fudhloli EC, Tuko GL, Swastiandari. The inventory control, storage facilities and distribution at pharmaceutical industry in supporting drugs availability of JKN Era. JMPF 2019; 9: 27-37.

[4] Seila AF. Spreadsheet simulation. Proceedings of the 2006 Winter Simulation Conference 2006; 11-18.

[5] Rizqi ZU, Aulia R. Evaluation of redesign layout using discrete event simulation (DES). Proceedings of the International Conference on Industrial Engineering and Operations Management 2019; 3203-3211.

[6] Ramadan H, Gio UP, Rosmaini E. Monte carlo simulation approach to determine the optimal solution of probabilistic supply cost. Joumal of Research in Mathematics Trends and Technology 2020; 2: 1-6.

[7] Widyadana IGAW, Tanudireja AD, Teng HM. Optimal inventory policy for stochastic demand using monte carlo simulation and evolutionary algorithm. JIRAE 2017. 2: 8-11.

[8] Andriansyah. Sentia PD. Sastri SE. Prasanti N. Decision making of inventory system using monte carlo simulation: a case study. International Journal of Conceptions on Computing and Information Technology 2018. 6: 5-7.

[9] Leepaitoon S. Bunterngchit C. The application of monte carlo simulation for inventory management: a case study of a retail store. International Journal of the Computer, the Internet and Management 2019. 27: 76-83.

[10] Belvárdi G. Király A. Varga T. Gyozsán Z. Abonyi J. Monte carlo simulation based performance analysis of supply chains. International Journal of Managing V alue and Supply Chains (IJMVSC) 2012. 3: 1-15.

[11] Karnon J, Stahl J, Brennan A, Caro JJ, Mar J, Moller J. Modelling using discrete event simulation: a report of the ISPOR-SMDM modeling good research practices task force-4. Medical Decision Making 2012: 5: 701-711.

[12] Hadi S. Statistik jilid 2; Yogyakarta: Penerbit Andi, 2004.

[13] Ižaríková G. Monte carlo simulation for anova. International Scientific Journal about Simulation 2016; 2: 11-15.

[14] Lin DY. An efficient monte carlo approach to assessing statistical significance in genomic studies. Bioinformatics 2004; 21: 781-787. 